\title{
Who Seeks Help Online for Self-Injury?
}

\author{
Dr. Mareka Frost ${ }^{1}$, Leanne Casey, $\mathrm{PhD}^{2}$, \\ ${ }^{1}$ Griffith University, School of Applied Psychology, Mt Gravatt, Brisbane, Australia,
}

${ }^{2}$ Griffith Health Institute, Brisbane, Australia

E-mail: 1.casey@griffith.edu.au

\begin{abstract}
Objectives: To identify differences between young people who seek help online for selfinjury and those who self-injure but do not seek help online, in order to improve online services for young people at high risk of suicide.

Methods: Young people reporting a history of self-injury $(\mathrm{N}=679)$ were identified as part of large study $(\mathrm{N}=1463)$ exploring help-seeking.

Results: One third of young people with a history of self-injury reported online helpseeking for self-injury. Online help-seekers were significantly more distressed, suicidal and had a greater degree of self-injury compared to those who did not seek help online. Conclusion: The Internet provides an important form of support to the most at risk young people in this population, and may be a proximal step to face-to-face help-seeking. Further research is required to investigate the forms of support currently accessed by young people online, and their effectiveness.
\end{abstract}

KEYWORDS: Deliberate Self-Harm, Self-Injury, Self-Injurious Behavior, eHealth, Internet

\section{INTRODUCTION}


Non-suicidal self-injury is associated with increased risk of suicide (Hawton \& James, 2005; Muehlenkamp \& Gutierrez, 2007). Young people with a history of self-injury report a greater need for help compared to their peers, but fewer of them engage in helpseeking (Evans, Hawton, \& Rodham, 2005). A number of factors may contribute to lower help-seeking in this population. Help-negation refers to a decrease in actual helpseeking or intentions to seek help as psychological distress rises (Rudd, Joiner, \& Rajab, 1995). Young people who self-injure have higher levels of psychological distress and suicidal ideation compared to their peers (Muehlenkamp \& Gutierrez, 2007), and therefore may be more susceptible to experiencing help-negation. Opportunities for informal help-seeking through family and friends may be limited in young people who self-injure, due to poor social support or prejudicial family environments (Martin, Bureau, Cloutier, \& Lafontaine, 2011; Warm, Murray, \& Fox, 2002). Previous research also indicates low levels of professional help-seeking, for example through psychologists, social workers or general practitioners (Fortune, Sinclair, \& Hawton, 2008; Madge et al., 2008). Young people with lower offline help-seeking are more likely to go online for suicide related support (Harris, McLean, \& Sheffield, 2009). It is possible this is also the case for young people who self-injure Polk \& Liss (2007) reported more severe and frequent self-injury in young people recruited online, compared to those recruited offline, although it is possible that some young people recruited offline may also have used the Internet to seek help for self-injury. An important first step in understanding online helpseeking in young people who self-injure is to identify who goes online for help and how these young people differ from their peers. 
Observational studies of the online behaviour of young adults who self-injure have identified a growing number of Internet message boards devoted to the topic of selfinjury (Whitlock, Later, \& Conterio, 2007; Whitlock, Powers, \& Eckenrode, 2006). In addition, the number of participants on message boards dedicated to self-injury has also been found to be rapidly increasing (Boeckmann, 2008). Previous research indicates that the Internet has the potential to increase risk of self-injury for some young people. (Rodham, Gavin, \& Miles, 2007; Smithson et al., 2011; Whitlock, 2009; Whitlock, et al., 2006). However, searches for common self-injury related terms yield primarily supportive recovery orientated information online (Swannell et al., 2010). Whether helpful or harmful, young people are attempting to seek help online in relation to selfinjury (Boeckmann, 2008; Whitlock, et al., 2007) therefore, greater understanding of this behaviour in order to target evidence based treatments is required.

The Internet is increasingly being used as a medium for providing interventions for a range of presenting concerns and in a variety of ways that extend beyond therapist guided interventions and offer alternative approaches such as psychoeducation, peer support and self-help (see Barak, Hen, Boniel-Nissim, \& Shapira, 2008 for a review). The use of the Internet in directly treating a wide range of problems has yielded promising results. Barak et al. (2008) conducted a meta-analysis of studies of the effectiveness of online interventions reported in empirical articles before 2006 and concluded that strong support exists for the development of Internet based interventions. 
Internet based interventions are increasingly being recognised as an innovative way to engage young people in help-seeking (Rickwood, 2007) and may fill a gap in terms of support for distressed young people when other services are unavailable (Santor, Poulin, LeBlanc, \& Kusumakar, 2007). Young people report feeling empowered online and more comfortable talking about sensitive topics (Furlong, 2009). The Internet provides increased anonymity, confidentiality, and access to information and users can be more actively involved in obtaining information and tailoring it to their needs (Kell, 2009). There is also a growing body of evidence to suggest that when young people are aware of web-based services, they will seek help online (Nicholas, Oliver, Lee, \& O'Brien, 2004) and that information obtained online may increase offline help-seeking behaviour (Burns, Durkin, \& Nicholas, 2008; Nicholas, et al., 2004; Santor, et al., 2007; Ybarra \& Suman, 2006). The Internet may provide a powerful tool through which to promote help-seeking by reducing concerns about stigma in relation to metal health issues and increasing young people's knowledge regarding the issues they are facing (Furlong, 2009; Griffiths \& Christensen, 2006; Klein \& Cook, 2010; Ranahan, 2010). Improved mental health literacy, combined with lowered barriers to help-seeking, may increase young peoples' ability to identify self-injury as a serious concern and to seek support.

Online help-seeking may be best understood using a pathway to care model through which, for some individuals, the provision of information online may facilitate helpseeking more generally, providing access to interventions and ultimately leading to reduced symptoms or improved health, while for others the Internet may be useful in actually providing interventions online (Santor, et al., 2007). Further to this, some young 
people may effectively solve their self-injury related problems without using the internet, while others may benefit from links to online services in order to facilitate initial helpseeking at all. Investigating who goes online for help in relation to self-injury and how these young people differ from their peers is essential in understanding how evidencebased services online may be best targeted.

As such, the aim of the present study was to identify the differences between young people with a history of self-injurious behaviour who have or have not sought help online in relation to self-injury. Specifically, this was an exploratory study aiming to examine differences in online and offline help-seeking behaviour, intentions to seek help in the future and risk factors for suicide including degree of self-injurious behaviour, psychological distress and suicidal ideation.

\section{METHOD}

\section{Participants}

Participants were recruited to complete an Internet survey via a variety of online and offline sources including: posters, flyers, a first year psychology subject pool, youth mental health related websites, through word of mouth and 'snowballing' via social media (Facebook, Twitter and Tumblr). Recruitment was strategically conducted throughout all states of Australia, including regional areas, with the assistance of young people volunteering with one of the partner organisations. Advertising indicated that the study related to help-seeking. Additional information was provided before commencing the study, which alerted young people to the inclusion of self-injury and suicide related 
questions within the research and provided direct contacts for appropriate services for young people seeking immediate support. Additional links were provided throughout the survey following any potentially triggering questions.. Consent was indicated by clicking into the survey. The survey link was clicked by 1,799 individuals. Three hundred and thirty six of these were outside the age range (14-25) or failed to proceed beyond the initial question. A sample of 1,463 remained. Self-injurious behaviour was reported by 679 young people. The current paper is based on this sub-sample of young people reporting a history of self-injurious behaviour. The project was approved by the Griffith University Human Ethics Committee.

\section{Measures}

\section{Psychological Distress}

General psychological distress was measured using the Kessler Psychological Distress Scale (K10). This 10-item measure assesses non-specific psychological distress in adolescents and adults and has good psychometric properties (Andrews \& Slade, 2001; Kessler et al., 2002). In the present study, internal consistency was high (coefficient alpha $=.92)$.

\section{Self-Injurious Behaviour}

The Self-Harm Behaviour Questionnaire (SHBQ) makes use of open questions regarding self-injurious behaviour, to reduce risks associated with detailing self-injury methods to young people (Gutierrez, 2006). In the present study, only one six item subscale, nonsuicidal self-injury (NSSI),was used (Plener, Libal, Keller, Fegert, \& Muehlenkamp, 
2009). The subscale was adapted for the online context. Questions assessed lifetime history of self-injury, method of self-injury, frequency, severity and onset of selfinjurious behaviour as well as lifetime disclosure of self-injury to anyone and need for medical assistance. A total score was obtained by summing all items. The subscale had good internal consistency in the current sample (coefficient alpha $=.94$ ).

\section{Suicidal Ideation}

Suicidal Ideation was assessed using four items: lifetime suicidal ideation; frequency of suicidal ideation over past 12 months; threat or disclosure of suicidal ideation or attempts; and self-reported likelihood of future suicidal behaviour (The Suicidal Behaviour Questionnaire-Revised [SBQ-R]). Items were summed to give a total score (Osman et al., 2001). Good internal consistency (coefficient alpha $=.86$ ) was found in the current sample.

\section{Help-Seeking Intentions}

Help-seeking intentions were measured using items adapted from the General HelpSeeking Questionnaire (GHSQ) (Wilson, Deane, Ciarrochi, \& Rickwood, 2005). The GHSQ has a matrix format and can be modified according to the purpose of the research (Wilson et al., 2007). The GHSQ was initially developed to assess intentions to seek help from a range of formal and informal sources for 'personal-emotional problems' and 'suicidal thoughts' (Wilson, et al., 2005). Weak but significant associations ( $r=.17$ to .48) were found between help-seeking intentions and actually seeking help from the corresponding source in the following three weeks (Wilson, et al., 2005). Potential 
sources of help included in the current paper were: parent or carer; friend (known in person); family friend or relative; partner, boyfriend, girlfriend; general medical practitioner (GP); mental health professional; telephone counselling; professional web or email counselling; and, Internet. A twelfth option was that they would not look for help or talk to anyone. For each of these, participants were asked to rate their intention to seek future help for self-injury on a 7-point Likert scale (from 1"extremely unlikely" to 7 "extremely likely"). Sources of help were then classified conceptually, in line with previous research (Wilson, 2010). Three variables were formed 'family and friends' (4 items, $M=3.20, S D=1.68$, coefficient alpha $=.82$ ), 'professionals' ( 2 items, $M=3.28$, $S D=1.92$, coefficient alpha $=.83$ ), 'technology-based' (3 items, $M=2.95, S D=1.70$, coefficient alpha $=.82$ ), and the single item indicating intention not to seek help from anyone $(M=4.35, S D=2.17)$.

\section{Analytic Procedure}

Independent-samples t-tests were used to investigate responses relating to demographic variables, history of self-injury and help-seeking experiences. The potential impacts of age, gender and psychological distress were then controlled using ANCOVA.

\section{RESULTS}

A history of self-injurious behaviour (intentional harm to self, without an intention to kill oneself) was reported by almost half $(46.41 \%, N=679)$ of the 1463 young people who completed the survey. To ensure consistent identification of self-injurious behaviour, participants were asked an open-ended follow-up question "What did you do?”. Two 
raters then coded responses using De Leo and Heller's (2004) criteria. One rater was the first author and the other a researcher experienced in the area of suicide prevention and youth mental health. The inter-rater agreement for both self-injurious behaviour (0.93) and thoughts of self-injury $(0.93)$ was high. Only $1.6 \%(N=11)$ of participants were found to have inaccurately rated their self-injurious behaviour.

The average age of the sub-sample who reported a history of self-injurious behaviour was 17.84 years $(S D=2.97)$. The proportion of females was .86 and the proportion giving their sexual orientation as heterosexual was .67. Most (62\%) indicated that they lived in a city or town. When compared to the Australian population, females were substantially over-represented ( $\mathrm{p}=.48$ nationally) and young people from rural, regional, and remote areas were slightly over-represented in this sub-sample ( $\mathrm{p}=.60$ nationally) (Muir et al., 2009).

Participants were compared according to whether or not they reported seeking help online for self-injurious behaviour. Using skip logic, all young people with a history of selfinjury were directed to a question regarding online help-seeking for self-injurious behaviour. The online help-seeking question was answered by 594 participants. Of these participants, $35.9 \%(N=213)$ reported online help-seeking for self-injury, while the remaining $64.1 \%(N=381)$ reported that they had not used the Internet to seek help in relation to self-injury. Online help-seekers were significantly younger than those who did not seek help online in relation to self-injury, $t(592)=-2.64, p=.009$. See Table 1 for further demographic comparisons. 
Independent-samples t-tests were conducted to compare psychological distress, suicidal ideation and self-injurious behaviour in young people who had and had not gone online for help in relation to self-injury behaviour. Young people who sought help online in relation to self-injurious behaviour were more distressed and had higher levels of suicidal ideation than those who had not sought help online in relation to self-injury (see Table 2). In addition, young people who sought help online in relation to self-injury had a higher level of overall self-injurious behaviour, more episodes of self-injury and had harmed themselves more recently (see Table 2). They were also more likely to have needed to see a doctor after having harmed themselves.

Further independent-samples t-tests indicated that online help-seekers were significantly less likely to have ever disclosed their self-injurious behaviour to someone (measured on the SHBQ). More than half of the young people $(54 \%, N=113)$ who had gone online looking for support in relation to self-injury reported a belief that there is more support available to them online than offline for self-injury related problems. In spite of this, online help-seekers indicated a greater intention to seek help for self-injurious behaviour in the future. When investigated by source of help, these young people were found to be less likely than those who had not looked online for help to seek help from family and friends, and more likely to seek help from technology-based sources, including the Internet. There was no difference in intentions to seek help from professionals (See Table $3)$. 
To ensure that the effects were not occurring due to differences in psychological distress, age or gender, these variables were controlled using ANCOVA. Young people who had been online for help indicated a significantly greater intention to seek help for selfinjurious behaviour, even after controlling for these factors, $F(1,579)=18.19, p<.001$. The difference in help-seeking intentions from family and friends in relation to selfinjurious behaviour was no longer significant, $F(1,579)=<.001, p=.99$. However, those who sought help on the Internet continued to be significantly more likely to seek help from technology-based sources, $F(1,579)=42.84, p<.001$. A significant difference in help-seeking intentions from professionals emerged, with online help-seekers $(M=2.88$, $S D=1.76$ ) indicating significantly higher intentions to seek professional help compared to individuals who did not seek help online $(M=2.62, S D=1.77), F(1,580)=$ $5.99, p=.02$.

\section{DISCUSSION}

The current research was the first to address differences between young people who seek help online in relation to self-injurious behaviour and young people who self-injure but do not seek help online. One third of young people with a history of self-injurious behaviour had used the Internet to seek help in relation to self-injury. Over half of these online help-seekers perceived that they had more support available to them online than offline. Online help-seekers had significantly higher psychological distress, suicidal ideation and self-injurious behaviour. They reported more frequent and recent selfinjurious behaviour and were more likely to have required medical help as a result of self-injury, compared to young people who had not sought help online. Given higher 
suicidal ideation and the significantly greater rate of repeated self-injurious behaviour in the online help-seeking group, it is likely that this group is at increased risk of suicide (Hawton \& James, 2005; Owens, Horrocks, \& House, 2002; Zahl \& Hawton, 2004).

Young people who sought help online in relation to self-injurious behaviour were less likely to have disclosed their self-injurious behaviour to anyone, compared to those who had not attempted to seek help online. This reflects a similar pattern of inhibited helpseeking in online help-seekers found in previous research (Harris, et al., 2009). That is, not seeking help from offline mental health professionals was a predictor of online helpseeking in young people with a range of problems (Harris, et al., 2009). Therefore, young people who seek help online in relation to self-injurious behaviour may be less likely to seek help from offline sources, compared to young people who do not seek help online.

Online support was accessed by young people most likely to be impacted by the helpnegation effect (Frost, 2012; Wilson, 2003, 2010; Wilson \& Deane, 2010). As such, young people least likely to access other help were the most likely to have been online seeking support in relation to self-injurious behaviour. This aligns with previous research indicating higher intentions to seek help online as distress increases (Ryan, Shochet, \& Stallman, 2010) and suggests that the internet may have an important role to play in mitigating help-negation in young people who self-injure.

Paradoxically, young people who sought help online in relation to self-injury indicated a significantly greater intention to seek help for self-injurious behaviour in the future, an 
effect which remained after controlling for age, gender and psychological distress. Before controlling for these factors, the higher intentions to seek help were found only for technology-based sources such as the Internet and phone help lines. However, after controlling for these variables, young people with online help-seeking for self-injurious behaviour were significantly more likely to intend to seek help from both technologybased sources and from mental health professionals.

Longitudinal research is required in order to understand this paradoxical finding. However, given that these young people were significantly less likely to have previously disclosed their self-injurious behaviour, it is possible that use of the Internet acts as a proximal step to offline help-seeking. In line with this, two-thirds of young people indicated that they would hope to use the Internet as a first step and would eventually like to be able to access offline support. The Internet may have a role in providing access to information from a range of sources in relation to distress, mental health concerns, selfinjury and help-seeking. This may assist in increasing mental health literacy and provide earlier access to information about the importance of seeking help (Christensen \& Griffiths, 2000). A desire for autonomy has been identified as one of the strongest barriers to help-seeking from a mental health professional among young people (Wilson \& Deane, 2012). It may be that young people first feel the need to attempt to resolve or understand their self-injury, or that the Internet provides a means through which to determine whether their self-injury is serious enough to warrant seeking help as well as providing information regarding how to do so. That is, the Internet may act as a gatekeeper to care for young people who are unable or unwilling to access traditional 
gatekeepers (e.g., parents). Assisting young people to increase their emotional competency and feel more confident in expressing their problems and concerns to others may increase help-seeking (Cigularov, Chen, Thurber, \& Stallones, 2008). Even if supports are available, young people need to be able to identify self-injury as a serious problem and be willing to seek support before they become acutely distressed in order to reduce the impact of help-negation (Wilson, Bushnell, \& Caputi, 2011). The internet may act as a key tool in providing information and initial support, thereby acting as a proximal step to offline help-seeking for this population.

Although the majority of young people with a history of self-injury indicated that they would eventually like to seek help offline, one third indicated that if they were to use the Internet to seek help for self-injury in the future, they would prefer to use the Internet to resolve their self-injury on their own. This preference aligns with a pathways to care model (Santor, et al., 2007), indicating the potential role of the internet both as an proximal step towards offline help-seeking for some young people and as a potential primary intervention for others. Therefore, it appears that online support services for selfinjury need to go beyond providing information and links to services and provide a range of support in order to assist young people who are unlikely to seek help in other ways. The importance of providing evidence based services online is highlighted given the high distress; suicidality; self-injurious behaviour; and lower disclosure of self-injury to offline sources found in online help-seekers. 
A number of limitations in relation to the present study should be noted. As the method of recruiting denotes, the study was targeted, rather than population-based and should not be interpreted as a representative survey.. Young people with previous contact with a mental health professional online are likely to have been over represented, as existing crisis support services participated in recruiting. In addition, there was a high percentage of female participants, for whom the rate of self-injurious behaviour is known to be higher than for males (Madge, et al., 2008). This may have contributed to the overall high rate of self-injury reported. The cross sectional nature of the research made it impossible to determine whether online help-seeking is causal in increased rates of distress. Longitudinal research is required to investigate this further.

\section{CONCLUSIONS}

The present study found that online help-seekers were significantly more distressed, had higher levels of suicidal ideation and a greater degree of self-jury compared to those who did not seek help online for self-injury. When considered in the context of research regarding help-negation, this indicated that young people who were least likely to seek help overall, were most likely to seek help online in relation to self-injury. The Internet provides an important form of support to the most at risk young people in this population, and may be a proximal step to face-to-face help-seeking. Further research is required to investigate the forms of support currently accessed by young people online, and their effectiveness.

\section{ACKNOWLEDGEMENTS}


The publication of this research was funded through a grant provided by the au. Domain Administration (auDA) Foundation. The authors also wish to acknowledge the contribution of a number of people in this research project. The young people who took the time to complete the online survey and assist with recruiting; BoysTown's Kids Helpline service and The Inspire Foundation's Reach Out service, who partnered on this research project; Natalie Spiteri Rando and Christian Frost for assistance with coding of data and editing; and Emeritus Professor John O’Gorman for his assistance with statistical consultation.

\section{REFERENCES}

Andrews, G., \& Slade, T. (2001). Interpreting scores on the Kessler Psychological Distress Scale (K10). Australian and New Zealand Journal of Public Health, 25, 494 497. doi: 10.1111/j.1467-842X.2001.tb00310.x

Barak, A., Hen, L., Boniel-Nissim, M., \& Shapira, N. a. (2008). A comprehensive review and a meta-analysis of the effectiveness of internet-based psychotherapeutic interventions. Journal of Technology in Human Services, 26(2-4), 109-160. doi: $10.1080 / 15228830802094429$

Boeckmann, E. L. (2008). Self-injury knowledge and peer perceptions among members of internet self-injury groups. Western Kentucky University, Bowling Green.

Burns, J. M., Durkin, L. A., \& Nicholas, J. (2008). Reach Out! The internet as a setting for mental health promotion and prevention. Eistech: Journal of the Irish Association of Counselling \& Psychotherapy, 8, 13-19. 
Christensen, H., \& Griffiths, K. M. (2000). The internet and mental health literacy. Australian and New Zealand Journal of Psychiatry, 34, 975-979. doi:

\section{$10.1080 / 000486700272$}

Cigularov, K., Chen, P. Y., Thurber, B. W., \& Stallones, L. (2008). What prevents adolescents from seeking help after a suicide education program? Suicide and Life Threatening Behavior, 38(1), 74-86. doi: 10.1521/suli.2008.38.1.74

De Leo, D., \& Heller, T. S. (2004). Who are the kids who self-harm? An Australian selfreport school survey. The Medical Journal of Australia, 181, 140-144.

Evans, E., Hawton, K., \& Rodham, K. (2005). In what ways are adolescents who engage in self-harm or experience thoughts of self-harm different in terms of help-seeking, communication and coping strategies? Journal of Adolescence, 28(4), 573-587. doi: 10.1016/j.adolescence.2004.11.001

Fortune, S. A., Sinclair, J., \& Hawton, K. (2008). Help-seeking before and after episodes of self-harm: A descriptive study in school pupils in England Frost, M. (2012). Self-harm, help-seeking and the Internet (unpublished doctoral dissertation). Griffith University, Brisbane.

Furlong, A. (Ed.). (2009). Handbook of youth and young adulthood: New perspectives and agendas. Routledge: Oxon.

Griffiths, K. M., \& Christensen, H. (2006). Review of randomised controlled trials of internet interventions for mental disorders and related conditions. Clinical Psychologist, 10(1), 16-29. doi: 10.1080/13284200500378696 
Gutierrez, P. M. (2006). Integratively assessing risk and protective factors for adolescent suicide. Suicide and Life Threatening Behavior, 36(2), 129-135. doi:

10.1521/suli.2006.36.2.129

Harris, K. M., McLean, J. P., \& Sheffield, J. (2009). Solving suicidal problems online:

Who turns to the Internet for help? Australian e-Journal for the Advancement of Mental

Health, 8(1). Retrieved from http://www.auseinet.com/journal/vol8iss 1/harrismclean.pdf

Hawton, K., \& James, A. (2005). Suicide and deliberate self harm in young people.

British Medical Journal, 330, 891-894. doi: 10.1136/bmj.330.7496.891

Kell, B. (2009). Internet and electronic approaches to research: The strengths and limitations of the internet as a health information resource for adolescents Abstracts, 44 20.

Kessler, R. C., Andrews, G., Colpe, L. J., Hiripi, E., Mroczek, D. K., Normand, S.-L. T., . .. Zaslavsky, A. M. (2002). Short screening scales to monitor population prevalences and trends in non-specific psychological distress. Psychological Medicine: A Journal of Research in Psychiatry and the Allied Sciences, 32(6), 959-976. doi:

$10.1017 / \mathrm{s} 0033291702006074$

Klein, B., \& Cook, S. (2010). Preferences for e-mental health services amongst an online Australian sample. Electronic Journal of Applied Psychology, 6(1), 27-38.

Madge, N., Hewitt, A., Hawton, K., Jan de Wilde, E., Corcoran, P., \& Fekete, S. (2008).

Deliberate self-harm within an international community sample of young people:

Comparative findings from the Child \& Adolescent Self-harm in Europe (CASE) Study. Journal of Child Psychology and Psychiatry, 49, 667-677. doi: 10.1111/j.14697610.2008.01879.x 
Martin, J., Bureau, J.-F., Cloutier, P., \& Lafontaine, M.-F. (2011). A comparison of invalidating family environment characteristics between university students engaging in self-injurious thoughts and actions and non-self-injuring university students. Journal of Youth and Adolescence, 40, 1477-1488. doi: 10.1007/s10964-011-9643-9

Muehlenkamp, J. J., \& Gutierrez, P. M. (2007). Risk for suicide attempts among adolescents who engage in non-suicidal self-injury. Archives of Suicide Research, 11(1), 69-82. doi: 10.1080/13811110600992902

Muir, K., Mullan, K., Powell, A., Flaxman, S., Thompson, D., \& Griffiths, M. (2009). State of Australia's young people: A report on the social, economic, health and family lives of young people. Commonwealth of Australia Retrieved from http://www.deewr.gov.au/Youth/OfficeForYouth/Documents/StateofYoungPeople.pdf. Nicholas, J., Oliver, K., Lee, K., \& O'Brien, M. (2004). Help-seeking behaviour and the internet: An investigation among Australian adolescents. Australian e-Journal for the Advancement of Mental Health, 3(1), 1-18. doi: 10.5172/jamh.3.1.16

Osman, A., Bagge, C. L., Gutierrez, P. M., Konick, L. C., Kopper, B. A., \& Barrios, F. X. (2001). The Suicidal Behaviors Questionnaire-Revised (SBQ-R):Validation with clinical and nonclinical samples. Assessment, 8(4), 443-454. doi: 10.1177/107319110100800409 Owens, D., Horrocks, J., \& House, A. (2002). Fatal and non-fatal repetition of self-harm. The British Journal of Psychiatry 181, 193-199. doi: 10.1192/bjp.181.3.193

Plener, P. L., Libal, G., Keller, F., Fegert, J. M., \& Muehlenkamp, J. J. (2009). An international comparison of adolescent non-suicidal self-injury (NSSI) and suicide attempts: Germany and the USA. Psychological Medicine: A Journal of Research in Psychiatry and the Allied Sciences, 39(9), 1549-1558. doi: 10.1017/s0033291708005114 
Polk, E., \& Liss, M. (2007). Psychological characteristics of self-injurious behaviour. Personality and Individual Differences, 43, 567-577. doi: 10.1016/j.paid.2007.01.003

Ranahan, P. (2010). Mental health literacy: A conceptual framework for future inquiry into child and youth care professionals' practice with suicidal adolescents. Child \& Youth Care Forum, 39(1), 11-25. doi: 10.1007/s10566-009-9087-5

Rickwood, D. (2007). Editorial. Clinical Psychologist. Special Issue: Youth mental health, 11(3), 71. doi: 10.1080/13284200801886066

Rodham, K., Gavin, J., \& Miles, M. (2007). I hear, I listen and I care: A qualitative investigation into the function of a self-harm message board. Suicide and Life Threatening Behavior, 37(4), 422-430. doi: 10.1521/suli.2007.37.4.422

Rudd, M. D., Joiner, T. E., \& Rajab, M. H. (1995). Help negation after acute suicidal crisis. Journal of Consulting and Clinical Psychology, 63(3), 499-503. doi: 10.1037/0022-006X.63.3.499 Ryan, M. L., Shochet, I. M., \& Stallman, H. M. (2010). Universal online interventions might engage psychologically distressed university students who are unlikely to seek formal help. Advances in Mental Health, 9(1), 73-83. doi: 10.5172/jamh.9.1.73 Santor, D. A., Poulin, C., LeBlanc, J. C., \& Kusumakar, V. (2007). Online health promotion, early identification of difficulties, and help seeking in young people. Journal of the American Academy of Child \& Adolescent Psychiatry, 46(1), 50-59.

Smithson, J., Sharkey, S., Hewis, E., Jones, R., Emmens, T., Ford, T., \& Owens, C. (2011). Problem presentation and responses on an online forum for young people who self-harm. Discourse Studies, 13(4), 487-501. doi: 10.1177/1461445611403356 
Swannell, S., Martin, G., Krysinska, K. E., Kay, T., Olsson, K., \& Win, A. (2010).

Cutting on-line: Self-injury and the internet. Advances in Mental Health, 9(2), 177-189. doi: 10.5172/jamh.9.2.177

Warm, A., Murray, C. D., \& Fox, J. (2002). Who helps? Supporting people who selfharm. Journal of Mental Health, 11(2), 121-130. doi: 10.1080/096382301200041533

Whitlock, J. (2009). The cutting edge: Non-suicidal self-injury in adolescence. Research fACTs and Findings, 9.

Whitlock, J., Later, W., \& Conterio, K. (2007). The internet and self-injury: What psychotherapists should know. Journal of Clinical Psychology, 63(11), 1135-1143. doi: 10.1002/jclp.20420

Whitlock, J., Powers, J. L., \& Eckenrode, J. (2006). The virtual cutting edge: The Internet and adolescent self-injury. Developmental Psychology, 42(3), 407-417. doi: $10.1037 / 0012-1649.42 .3 .407$ Wilson, C. J. (2003). Help-negation for suicidal thoughts in sub-clinical samples of young people. $\mathrm{PhD}$, Univerisity of Wollongong.

Wilson, C. J. (2010). General psychological distress symptoms and help-avoidance in young Australians. Advances in Mental Health, 9(1), 63-72. doi: 10.5172/jamh.9.1.63 Wilson, C. J., Bushnell, J. A., \& Caputi, P. (2011). Early access and help seeking: practice implications and new initiatives. Early Intervention in Psychiatry, 5(Suppl. 1), 34-39. doi: 10.1111/j.1751-7893.2010.00238.x

Wilson, C. J., \& Deane, F. P. (2010). Help-negation and suicidal ideation: The role of depression, anxiety and hopelessness. Journal of Youth and Adolescence, 39(3), 291-305. doi: $10.1007 / \mathrm{s} 10964-009-9487-8$ 
Wilson, C. J., \& Deane, F. P. (2012). Brief report: Need for autonomy and other perceived barriers relating to adolescents' intentions to seek professional mental health care. Journal of Adolescence, 35, 233-237. doi: 10.1016/j.adolescence.2010.06.011 Wilson, C. J., Deane, F. P., Ciarrochi, J., \& Rickwood, D. (2005). Measuring helpseeking intentions: Properties of the General Help-Seeking Questionnaire. Canadian Journal of Counselling, 39(1), 15-28.

Ybarra, M. L., \& Suman, M. (2006). Help seeking behavior and the internet: A national survey. International Journal of Medical Informatics, 75, 29-41. doi: 10.1016/j.ijmedinf.2005.07.029

Zahl, D. L., \& Hawton, K. (2004). Repetition of deliberate self-harm and subsequent suicide risk: Long-term follow-up study of 11,583 patients. British Journal of Psychiatry, 185(1), 70-75. doi: 10.1192/bjp.185.1.70 
Table 1 Demographic Characteristics of Young People with Self-Injurious Behaviour by Online Help-Seeking Group

\begin{tabular}{|c|c|c|c|c|}
\hline Characteristic & Online Help-Seeking & $\begin{array}{l}\text { No Online } \\
\text { Help-Seeking }\end{array}$ & Overall (Mean/\%) & Total N \\
\hline Age & $17.57(2.90)$ & $18.24(3.0)$ & $18.00(2.98)$ & 594 \\
\hline \multicolumn{5}{|l|}{ Gender } \\
\hline Male & $6.1 \%$ & $15.2 \%$ & $12.0 \%$ & 71 \\
\hline Female & $91.5 \%$ & $83.5 \%$ & $86.4 \%$ & 513 \\
\hline Other & $2.3 \%$ & $1.3 \%$ & $1.7 \%$ & 10 \\
\hline ATSI & $4.2 \%$ & $2.1 \%$ & $2.9 \%$ & 17 \\
\hline CALD & $12.2 \%$ & $11.8 \%$ & $12.0 \%$ & 71 \\
\hline \multicolumn{5}{|l|}{ Sexual Orientation } \\
\hline Heterosexual & $58.7 \%$ & $70.3 \%$ & $66.1 \%$ & 392 \\
\hline${ }^{a}$ Non-Heterosexual & & $29.7 \%$ & $33.9 \%$ & 201 \\
\hline \multicolumn{5}{|l|}{ Location } \\
\hline Metropolitan & $58.7 \%$ & $65.5 \%$ & $63.1 \%$ & 231 \\
\hline RRR & $37.5 \%$ & $31.9 \%$ & $33.9 \%$ & 201 \\
\hline Other & $3.8 \%$ & $2.6 \%$ & $3.0 \%$ & 18 \\
\hline
\end{tabular}

Note. Age listed by Mean (SD). Other demographics listed by \% total for group.

${ }^{a_{6}}$ Non-Heterosexual' includes identification as gay, lesbian, bisexual, unsure or not wishing to identify with any of the options provided; ATSI = Aboriginal and Torres Strait Islander; CALD = Culturally and Linguistically Diverse; RRR = Rural, Regional, Remote. 
Table 2 Distress, Suicidal Ideation and Self-Injurious Behaviour by Online Help-Seeking Group

\begin{tabular}{|c|c|c|c|c|c|}
\hline Variable & Online Help & $N$ & Mean $(S D)$ & $t$ & $\mathrm{df}$ \\
\hline \multirow[t]{4}{*}{ Psychological Distress } & Yes & 211 & 35.27 & $9.08 * * *$ & 501.73 \\
\hline & & & $(7.65)$ & & \\
\hline & No & 380 & 28.86 & & \\
\hline & & & $(9.17)$ & & \\
\hline \multirow[t]{3}{*}{ Suicidal Ideation } & Yes & 211 & 12.57 & $10.52 * * *$ & 589 \\
\hline & & & $(3.57)$ & & \\
\hline & No & 380 & $9.03(3.94)$ & & \\
\hline \multirow[t]{2}{*}{ Total SIB } & Yes & 212 & $14.70(1.71)$ & \multirow[t]{2}{*}{$9.03 * * *$} & \multirow[t]{2}{*}{507.37} \\
\hline & No & 375 & $13.08(2.37)$ & & \\
\hline \multirow[t]{2}{*}{ Episodes } & Yes & 213 & $5.34(1.19)$ & \multirow[t]{2}{*}{$11.12 * * *$} & \multirow[t]{2}{*}{582.70} \\
\hline & $\mathrm{N}$ & 378 & $3.93(1.90)$ & & \\
\hline \multirow[t]{2}{*}{ Last SIB } & & 152 & $1.78(.99)$ & \multirow[t]{2}{*}{$-3.08 * *$} & \multirow[t]{2}{*}{326} \\
\hline & No & 176 & $2.13(1.02)$ & & \\
\hline \multirow[t]{2}{*}{ Disclosure } & Yes & 213 & $1.20(.40)$ & \multirow[t]{2}{*}{$-4.89 * * *$} & \multirow[t]{2}{*}{512.55} \\
\hline & No & 381 & $1.38(.49)$ & & \\
\hline \multirow{2}{*}{ GP } & Yes & 213 & $2.34(.47)$ & \multirow[t]{2}{*}{$3.98 * * *$} & \multirow[t]{2}{*}{372.86} \\
\hline & No & 381 & $2.19(.39)$ & & \\
\hline
\end{tabular}

Note. $* * * p<.001 . * * p<.01$.

GP $=$ General Medical Practitioner 
Table 3 Intentions to Seek Help for Self-Injury by Online Help-Seeking Group

\begin{tabular}{|l|l|l|l|l|l|}
\hline Variable & Online Help & $N$ & Mean $(S D)$ & $t$ & df \\
\hline Help-Seeking Intentions & Yes & 212 & $33.47(11.27)$ & $2.60^{*}$ & 487.72 \\
\cline { 2 - 4 } & No & 375 & $30.81(12.89)$ & & \\
\hline Friends/Family & Yes & 212 & $2.31(1.24)$ & $-2.76^{* *}$ & 505.77 \\
\cline { 2 - 4 } & No & 375 & $2.63(1.49)$ & & \\
\hline Professional & Yes & 213 & $2.87(1.76)$ & 1.58 & 586 \\
\cline { 2 - 4 } & No & 375 & $2.63(1.77)$ & & \\
\hline Technology-Based & Yes & 212 & $3.21(1.77)$ & $5.52 * * *$ & 394.31 \\
\cline { 2 - 4 } & No & 375 & $2.41(1.56)$ & & \\
\hline
\end{tabular}

Note. ${ }^{* * *} p<.001 .{ }^{* *} p<.01 .{ }^{*} p<.05$. 